Article

\title{
The Fto Gene Regulates the Proliferation and Differentiation of Pre-Adipocytes in Vitro
}

\author{
Yang Jiao ${ }^{1,2,+}$, Jingying Zhang ${ }^{2,+}$, Lunjie Lu ${ }^{2}$, Jiaying $\mathrm{Xu}^{1}$ and Liqiang Qin ${ }^{3, *}$ \\ 1 Collaborative Innovation Center of Radiological Medicine of Jiangsu Higher Education Institutions, Medical \\ College of Soochow University, Suzhou 215123, China; jiaoyang@suda.edu.cn (Y.J.); \\ xujiaying@suda.edu.cn (J.X.) \\ 2 Department of Radiation Genetics, School of Radiation Medicine and Protection, Medical College of \\ Soochow University, Suzhou 215123, China; 15850122119@163.com (J.Z.); 1lj19900622@163.com (L.L.) \\ 3 Department of Nutrition and Food Hygiene, School of Public Health, Medical College of Soochow \\ University, Suzhou 215123, China \\ * Correspondence: qinliqiang@suda.edu.cn; Tel.: +86-512-6588-0073 \\ + These authors contributed equally to this work.
}

Received: 20 October 2015; Accepted: 15 February 2016; Published: 19 February 2016

\begin{abstract}
The highly regulated differentiation and proliferation of pre-adipocytes play a key role in the initiation of obesity. Fat mass and obesity associated (FTO) is a novel gene strongly associated with the risk of obesity. A deficiency of FTO may cause growth retardation in addition to fat mass and adipocyte size reduction in vivo. To investigate the potential role of Fto gene on the proliferation and differentiation of pre-adipocytes, we generated Fto-knockdown and overexpressed 3T3-L1 cells. Using numerous proliferation assays our results suggest that Fto knockdown leads to suppression of proliferation, lower mitochondrial membrane potential, less cellular ATP, and decreased and smaller intracellular lipid droplets compared with controls $(p<0.05)$. Western blot analysis demonstrated that Fto knockdown can significantly suppress peroxisome proliferator-activated receptor gamma (PPAR $\gamma$ ) and glucose transporter type 4 (GLUT4) expression and inhibit Akt phosphorylation. By contrast, overexpression of Fto had the opposing effect on proliferation, mitochondrial membrane potential, ATP generation, in vitro differentiation, Akt phosphorylation, and PPAR $\gamma$ and GLUT4 expression. Moreover, we demonstrated that Wortmannin, a phosphoinositide 3-kinase (PI3K) inhibitor, could inhibit phospho-Akt in Fto overexpressed 3T3-L1 cells. Taken together, the results suggest that Fto regulates the proliferation and differentiation of 3T3-L1 cells via multiple mechanisms, including PPAR $\gamma$ and PI3K/Akt signaling.
\end{abstract}

Keywords: obesity; Fto; pre-adipocyte; proliferation; differentiation

\section{Introduction}

Obesity increasingly is a pressing public health concern with a rapidly surging prevalence in both developed and developing countries [1-3]. According to the World Health Organization, in 2014 more than 1.9 billion adults were overweight, 600 million of whom were obese [4]. In addition to psychosocial ramifications of obesity, this condition causes a multitude of health complications [1-3]. It has been widely reported that the majority of obese individuals have multiple comorbidities including inflammation, hypertension, coronary heart disease and stroke, type 2 diabetes mellitus, insulin resistance, gall bladder disease, nonalcoholic fatty liver disease, and cancers, among others. Together, these result in the poor health of those affected and may result in accelerated aging and death [3,5].

Unfortunately, the existing interventions for obesity control, including diet modification and exercise-based managements, seem largely ineffective [5], in part related to our inadequate and 
incomplete understanding of mechanisms of pathogenesis. It has been well accepted that adipose tissues play an integral role in lipid and glucose metabolism; therefore precise regulation of differentiation and proliferation of pre-adipocytes are thought to play a key role in the initiation of obesity [6-11]. Recently, the molecular mechanisms and signaling pathways regulating pre-adipocytes differentiation and proliferation have been extensively studied; however, our understanding of these processes remains incomplete $[10,12]$.

The fat mass and obesity associated gene (Fto) is an important genes that is strongly associated with the risk for obesity $[13,14]$. In vivo experiments have demonstrated that Fto-deficiency causes growth retardation in addition to fat mass and adipocyte size reduction [15]. Furthermore, overexpression or dysregulation of Fto alleles is associated with increased risk of obesity while inhibition of Fto may have a protective-effect against obesity in animal models [15-17]. Recently, several studies have highlighted the importance of Fto gene during adipogenesis [18-20]. Zhao et al. [18] suggested Fto can modulate SRSF2-RNA binding and demethylation of N6-methyladenosine, which together impact RNA splicing and critically regulate adipogenesis. Tews et al. [19] hypothesized that Fto deficiency may lead to the induction of white adipose tissue (WAT) browning and in turn cause mitochondrial uncoupling and increase energy expenditure. Taken together, this suggests an FTO-associated susceptibility to obesity. Merkestein et al. [20] reported that FTO promotes adipogenesis via mitotic clonal expansion. However, the specific mechanisms and signaling pathways by which FTO impacts adipogenesis and obesity remains incompletely characterized.

In the present study, the pre-adipose cell line 3T3-L1 was utilized as an in vitro model, and the biological roles and potential mechanisms of Fto on the proliferation and differentiation of pre-adipocytes were evaluated via classical gain/loss-of-function experiments.

\section{Materials and Methods}

\subsection{Cell Culture and Transfection}

The 3T3-L1 cell line was originally obtained from American Type Culture Collection (ATCC, Manassas, VA, USA). Cells were cultured in high-glucose Dulbecco's modified eagle's media (Gibco, Grand Island, NY, USA), supplemented with $10 \%$ fetal bovine serum, L-glutamine (2 $\mathrm{mmol} / \mathrm{L})$, non-essential amino acids $(2 \mathrm{mmol} / \mathrm{L})$, penicillin $(100 \mathrm{U} / \mathrm{mL})$ and streptomycin $(100 \mathrm{U} / \mathrm{mL})$ (Gibco, Grand Island, NY, USA). Cells were grown in a humidified atmosphere with 5\% $\mathrm{CO}_{2}$ at $37^{\circ} \mathrm{C}$. Culture medium was replaced every 2 days, and cells were sub-cultured every 3-4 days. Used for this study are 3T3-L1 cells within 15 passages.

Using the genomic sequence of the mouse Fto gene (GeneBank ID: 26383), an Fto recombinant plasmid construction was constructed as previously described [21]. Three Fto siRNAs and a negative control siRNA (NC siRNA) were designed and synthesized (Invitrogen, Carlsbad, CA, USA). The Fto inhibition efficiency by siRNA was evaluated by qRT-PCR and Western blot assay. The siRNA \#2 elicited the most effective suppression of Fto and was selected for subsequent studies. The sequences for Fto-siRNA \#2 is as follows ( $5^{\prime}$ to $\left.3^{\prime}\right)$ :

\section{GCAUGUCAGACCUUCCUAATT \\ UUAGGAAGGUCUGACAUGCTT.}

The siRNA and plasmid transfections were performed using Lipofectamine ${ }^{\circledR 2000}$ (Thermofisher scientific, Waltham, MA, USA) according to the manufacturers' instructions. Briefly, 3T3-L1 cells $\left(2 \times 10^{5}\right)$ were seeded onto 6-well plates and incubated overnight. Then $30 \mathrm{nM}$ siRNAs and NC control, as well as $0.5 \mu \mathrm{g}$ plasmid DNA were applied to each well together with recommended volume of transfection reagent. Cells were harvested at indicated time points following transfection.

\subsection{Reverse Transcription and Quantitative Real Time PCR}

Total RNA was isolated according to the TRIZOL method (Invitrogen, Carlsbad, CA, USA). First-strand cDNA was synthesized from $1 \mu \mathrm{g}$ of total RNA using Hiscript ${ }^{\mathrm{TM}} 1$ st strand cDNA 
synthesis kit (Vazyme, Nanjing, CHN). Real time PCR was performed in Applied Biosystems 7500FAST RT-PCR system using SYBR Green (Thermofisher scientific, Waltham, MA, USA). The sequence of all Primers was as follows: Fto-Forward, 5'-GACACTTGGCTTCCTTACCAG-3' and Fto-Reverse, 5'-CTCACCACGTCCCGAAACAA-3'; and GAPDH-Forward, 5'-GGTTGTCTCCTGCGACTTCA-3', and GAPDH-Reverse, 5'-TGGTCCAGGGTTTCTTACTCC-3'. The expression of the Fto gene was calculated with the method of $2^{-\triangle \Delta C T}$.

\subsection{Western Blot Assay}

As previously described [22], cells were collected, washed in ice-cold PBS and lysed in $50 \mu \mathrm{L}$ of lysis buffer with protease inhibitor cocktail (Roche Life Science, Indianapolis, IN, USA). The protein concentration was determined using the BSA assay, and $50 \mu \mathrm{g}$ total protein for each sample was separated by SDS-polyacrylamide gel electrophoresis. The protein was transferred onto polyvinylidene fluoride (PVDF, Millipore, Billerica, MA, USA) microporous membranes, incubated with primary antibody overnight at $4{ }^{\circ} \mathrm{C}$, and subsequently incubated with the corresponding secondary antibodies. The primary antibodies used include rabbit anti-FTO (5-2H10, Abcam, Cambridge, MA, USA, 1:1000), rabbit anti-PPAR $\gamma$ (Abcam, polyclonal, ab19481, 1:400), rabbit anti-phospho-Akt (Ser473) (D9E, cell signaling technology, Danvers, MA, USA, 1:2000), rabbit anti-Glucose Transporter GLUT4 (Abcam, polyclonal, ab654, 1:2000), mouse anti-AMPK (Abcam, 34.2, 1:1000), rabbit anti-Adipose Triglyceride Lipase antibody (ATGL) (Abcam, EPR3444(2), 1:1000), HSL Antibody (cell signaling technology, polyclonal, 4107, 1:1000), rabbit anti-CREB (cell signaling technology, 48H2, 1:1000), rabbit anti-phospho-CREB(Ser133) (cell signaling technology, 87G3, 1:1000) and anti- $\beta$-actin (Beyotime Biotechnology, Haimen, China). Secondary antibodies include goat anti-mouse and anti-rabbit HRP (horseradish peroxidase)-conjugated antibodies (1:1000, Beyotime Biotechnology, Haimen, China).

\subsection{Cell Viability Assay}

As previously described, MTT (3-(4,5-Dimethylthiazol-2-yl)-2,5-diphenyltetrazolium bromide, a tetrazole) was used to evaluate cell viability [22]. In brief, cells were seeded at a density of $5 \times 10^{4}$ cells/well in 24-well plates. Following various treatments, $5 \mathrm{mg} / \mathrm{mL}$ MTT (Sigma-Aldrich, MO, USA) was added at indicated time points. After $4 \mathrm{~h}$ of incubation, the supernatant was discarded, and DMSO was added to dissolve the formazan generated. Absorbance at $490 \mathrm{~nm}$ was measured using multimode microplate reader (BioTek, VT, USA). Cell viability was expressed as the percentage of viable cells with different treatments relative to cell viability detected in the control cells.

\subsection{5-Ethynyl-2'-deoxyuridine (EdU) Cell Proliferation Assay}

Cells were seeded at a density of $8 \times 10^{3}$ onto 96-well plates, and exposed to $50 \mu \mathrm{M}$ of EdU $24 \mathrm{~h}$ following transfection (RiboBio, Guangzhou, China). After fixation with $4 \%$ paraformaldehyde and permeabilization with $0.5 \%$ Triton X-100, cells were incubated with $1 \times$ Apollo reaction cocktail for $30 \mathrm{~min}$ at room temperature followed by Hoechst 33342 staining. Cell proliferation was analyzed under an inverted fluorescent microscope (Olympus IX73, Tokyo, Japan) using cellSens Standard imaging software (Olympus, Tokyo, Japan).

\subsection{Flow Cytometry Assay}

Based on flow cytometry assay, JC-1 (Beyotime Biotechnology, Haimen, China) staining was used to measure the mitochondrial membrane potential $(\Delta \psi \mathrm{m})$ of 3T3-L1 cells according to the manufacturer's directions. Briefly, after indicated treatments, cells were collected from 6-well plates and incubated with $1 \mathrm{~mL} \mathrm{JC}-1$ working solution for $20 \mathrm{~min}$ at $37^{\circ} \mathrm{C}$. Cells treated with $10 \mu \mathrm{mol} / \mathrm{L}$ carbonyl cyanide m-chlorophenylhydrazone (CCCP) were used as negative control. The cells were then rinsed twice with JC-1 staining buffer, and the fluorescence intensity of both mitochondrial JC-1 monomers $\left(\lambda_{\mathrm{ex}} 514 \mathrm{~nm}, \lambda_{\mathrm{ex}} 529 \mathrm{~nm}\right)$ and aggregates $\left(\lambda_{\mathrm{ex}} 585 \mathrm{~nm}, \lambda_{\mathrm{em}} 590 \mathrm{~nm}\right)$ were detected using 
flow cytometer (FC500, Beckman Coulter, Indianapolis IN, USA). The ratio of aggregated JC-1 and monomeric JC-1 represented $\Delta \psi \mathrm{m}$ of 3T3-L1 cells.

\subsection{Live Cell Fluorescent Imaging of Mitochondria}

MitoTracker Red CM- $\mathrm{H}_{2} \mathrm{X}_{\mathrm{Ros}}$ (Thermofisher Scientific, Waltham, MA, USA) was applied to stain mitochondria of living cells. Cells were cultured in $35 \mathrm{~mm}$ glass bottom culture dishes (Nest Scientific, Rahway, NJ, USA) and incubated with $200 \mathrm{ng} / \mathrm{mL}$ MitoTracker Red $\mathrm{CM}-\mathrm{H}_{2} \mathrm{X}_{\mathrm{Ros}}$ at $37^{\circ} \mathrm{C}$ for $30 \mathrm{~min}$. Hoechst33342 $(0.5 \mu \mathrm{g} / \mathrm{mL})$ was used for nucleus staining. The images were observed using a laser scanning confocal microscopy and FV10-ASW 4.2 software (Olympus FV1200, Tokyo, Japan).

\subsection{ATP Assay/Determination of ATP Content of Cells}

According to ATP Assay Kit (Beyotime, BioTECH, Haimen, China), 3T3-L1 cells were lysed using commercial lysis buffer for $5 \mathrm{~min}$ on ice. Following centrifugation at $12,000 \times \mathrm{g}$ for $5 \mathrm{~min}$, reconstituted luciferase substrate was added to the supernatant and incubated for $5 \mathrm{~min}$ in the dark. Per 6-well plate, $50 \mu \mathrm{L}$ of each sample was mixed with $100 \mu \mathrm{L}$ ATP detection working dilution. The luminance (RLU) was measured using a multimode microplate reader. Standard curves were generated, and the protein concentration of each sample was determined using the Bradford Protein assay (Thermofisher Scientific, Waltham, MA, USA). Total ATP levels were expressed as nmol/mg protein.

\subsection{Cell Differentiation Assay and Oil Red O staining}

3T3-L1 cells were transfected with siRNA and Fto recombinant plasmid or with control siRNA and vector plasmid for $24 \mathrm{~h}$. The cells were incubated in differentiation media I (Dulbecco's modified eagle's media with $10 \%$ fetal bovine serum, containing $0.25 \mu \mathrm{g} / \mathrm{ml}$ insulin, $1 \mu \mathrm{M}$ Dexamethasone, and $0.5 \mathrm{mM}$ 3-Isobutyl-1-methylxanthine [IBMX] (Sigma-Aldrich, St. Louis, MO, USA)) for 2 days and then cultured in differentiation media II ((Dulbecco's modified eagle's media containing $10 \%$ fetal bovine serum and $0.25 \mu \mathrm{g} / \mathrm{mL}$ insulin). The cells were fed every other day with differentiation media II until the lipid droplets were formed. Cells were fixed for $20 \mathrm{~min}$ in 10\% formaldehyde and washed twice in phosphate-buffered saline and then stained in Oil Red O working solution (Abcam, Cambridge, MA, USA) for $1 \mathrm{~h}$. The red lipid droplets were observed under the microscope and were photographed after rinsing cells twice with PBS.

\subsection{Statistical Analysis}

All data were presented as mean \pm standard deviation, and all experiments were performed in triplicate. The statistical significance of differences was evaluated with the student's t-test or one-way analysis of variance (ANOVA) using SPSS Statistics (Version 19.0, IBM, Armonk, NY, USA). $p<0.05$ was considered significant.

\section{Results}

\subsection{Fto Gene Affects the Proliferation of 3T3-L1 Cells}

The expression level of mouse Fto was confirmed by real time PCR and Western blot assay. Our results demonstrate that Fto siRNA transfection effectively suppressed Fto at both mRNA and protein level (Figure 1A,B), while the recombinant plasmid transfection increased Fto expression in 3T3-L1 cells (Figure 1C,D). 
A

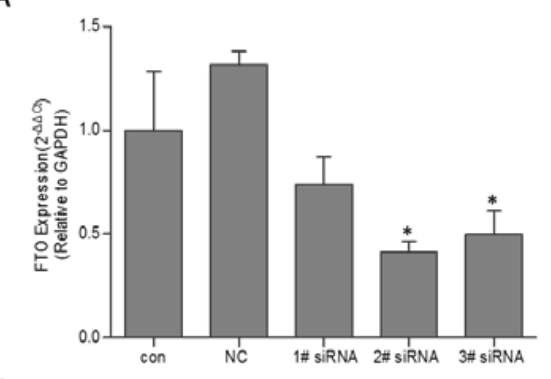

B

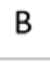

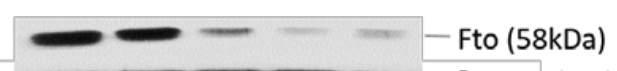

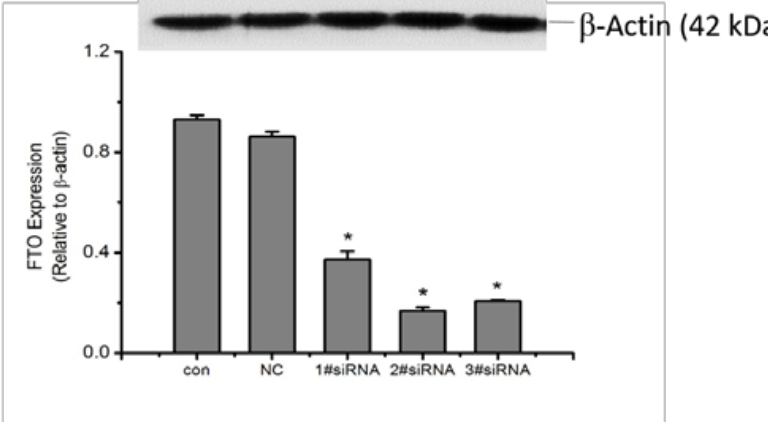

C

Figure 1. Construction of Fto knockdown or overexpressed pre-adipocyte model: (A) 3T3-L1 cells were transfected with siRNA control or three Fto specific siRNAs for $24 \mathrm{~h}$. Fto mRNA was identified using qRT-PCR, with GAPDH as control gene. The value of $2^{-\triangle \Delta C T}$ was represented as Means $\pm \mathrm{SD}$ of three independent analyses. ${ }^{*} p<0.05$, versus NC group. (B) Western blot was applied to determine the Fto protein expression. The expression level was quantified as fold changes in grey value, with $\beta$-actin as the loading control. ${ }^{*} p<0.05$, versus NC group. (C) The Fto mRNA expression and (D) protein expression level in 3T3-L1 cells were separately detected $24 \mathrm{~h}$ after transient transfection of pcDNA3.1-Fto or empty pcDNA3.1 vector, as described above. ${ }^{*} p<0.05$ versus empty pcDNA3.1 vector group.

The effect of Fto expression on the proliferation of pre-adipose cells was evaluated by MTT cell viability assay and using an EdU proliferation assay. As shown in Figure 2, when Fto expression was suppressed, the viability of 3T3-L1 cells was significantly reduced as compared to NC siRNA transfected cells (Figure 2A) $(p<0.05)$. By contrast, Fto recombinant plasmid increased the cell viability relative to the control transfected group $(p<0.05)$ (Figure $2 \mathrm{~B}$ ).

Moreover, cell EdU proliferation assay was performed $24 \mathrm{~h}$ after adipogenic induction. Our results indicate that pre-adipocytes with Fto-inhibition were less proliferative $24 \mathrm{~h}$ following adipogenesis induction as compared to NC control. However, Fto overexpression, induced by recombinant plasmid transient transfection, increased the proliferation of 3T3-L1 cells, as early as $24 \mathrm{~h}$ after adipogenesis induction (Figure 2C,D). Our data were consistent with the study by Merkestein et al. [20], which demonstrated that FTO acts early in adipogenesis to enhance adipocyte number. Taken together, these results demonstrate that Fto may regulate the proliferation of pre-adipocytes as well as the cell proliferation during early adipogenesis in vitro. 


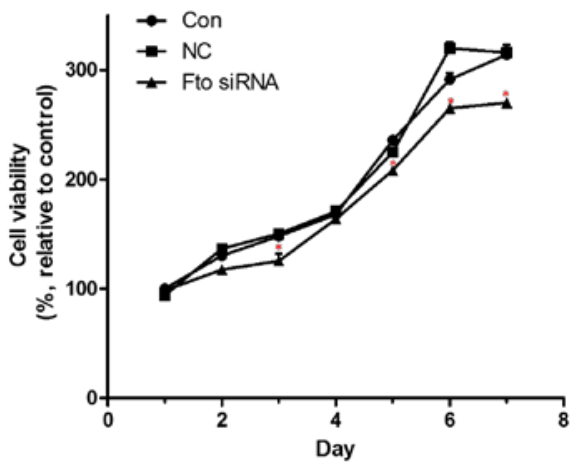

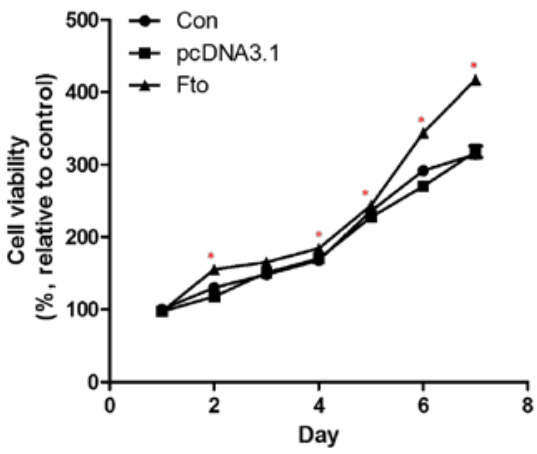

NC control
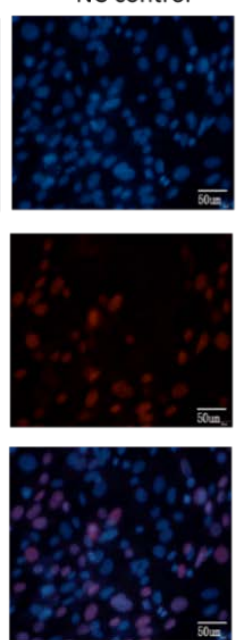

Fto siRNA
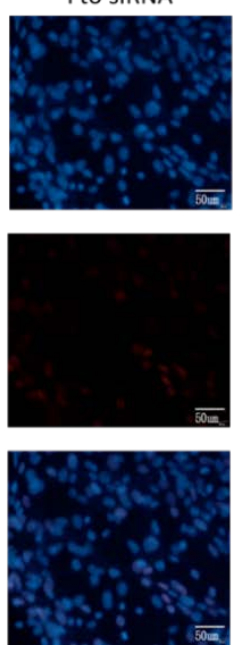

pcDNA3.1

pcDNA3.1/Fto
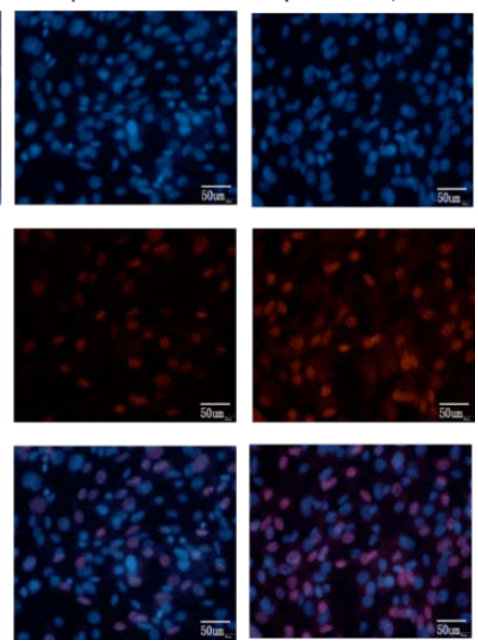

D

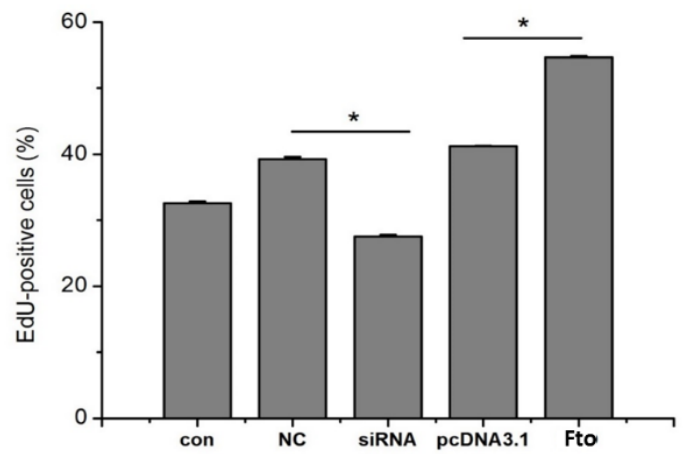

Figure 2. Fto affected 3T3-L1 cell proliferation. 3T3-L1 cells were transfected with Fto siRNA and NC siRNA (A), or transfected with Fto expression plasmid and vacant plasmid pcDNA3.1 (B) for $24 \mathrm{~h}$. Cells were seeded in 24-well plates and were counted at Day 1 to Day 7, respectively. Cell viability was expressed as the percentage of viable cells relative to cell viability detected in the mock transfected control cells. All samples were detected in triplicate. ${ }^{*} p<0.05$, versus control. (C) 3T3-L1 cells were transfected with siRNA and plasmid for $24 \mathrm{~h}$, and after adipogenic induction for another $24 \mathrm{~h}$, then the cell proliferation was analyzed via EdU incorporation. The representative images were shown as above; EdU (Red), Hoechest 33342 (blue); scale bar, $50 \mu \mathrm{M}$. (D) Quantification analysis of EdU positive cells.

\subsection{Fto Gene Influences the Mitochondrial Membrane Potential and ATP Levels of Pre-adipocytes}

The cellular metabolism, mitochondrial membrane potential (MMP) and cellular ATP levels of 3T3-L1 cells were determined as previously described [23]. As shown in Figure 3, 24 h following 
transfection, 3T3-L1 cells with different Fto gene expression levels exhibited different MMP levels. Specifically, 3T3-L1 cells with suppressed Fto expression demonstrated a 30\% lower MMP level than NC siRNA transfected cells (Figure 3A) while MMP levels in Fto-overexpressed cells were 40\% higher than in vector transfected control cells (Figure 3B). These results indicate that Fto is involved in the regulation on MMPs of adipocyte precursors.

A

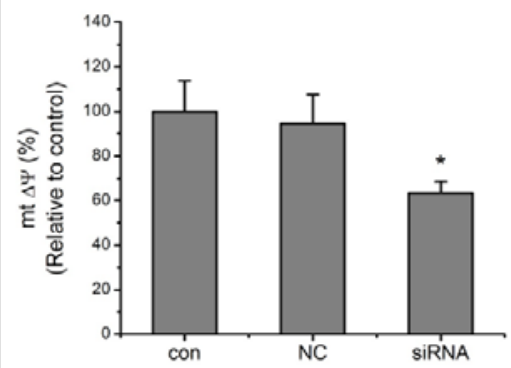

C

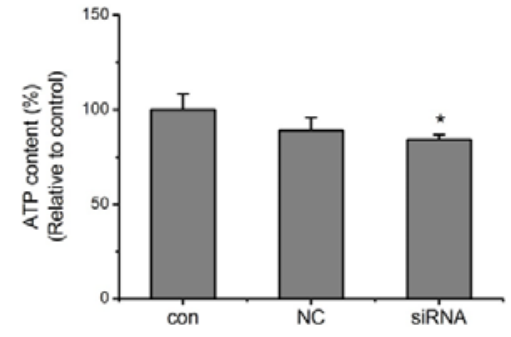

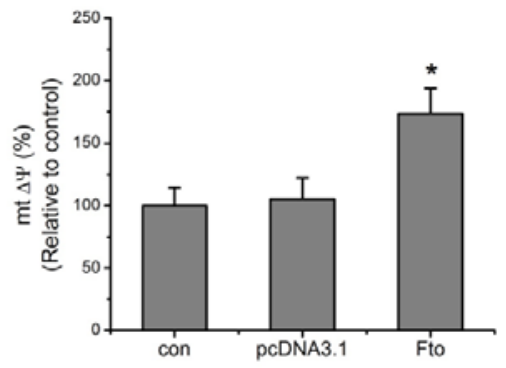

D

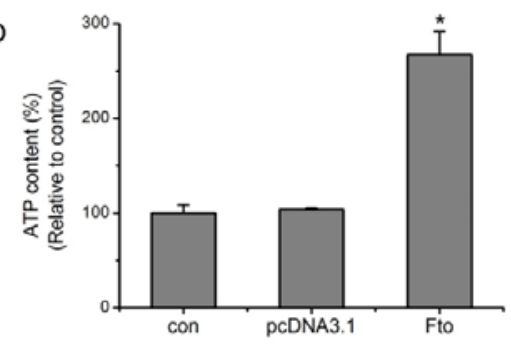

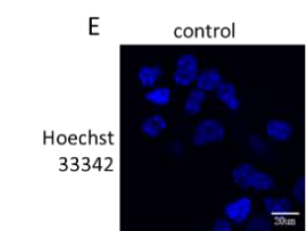
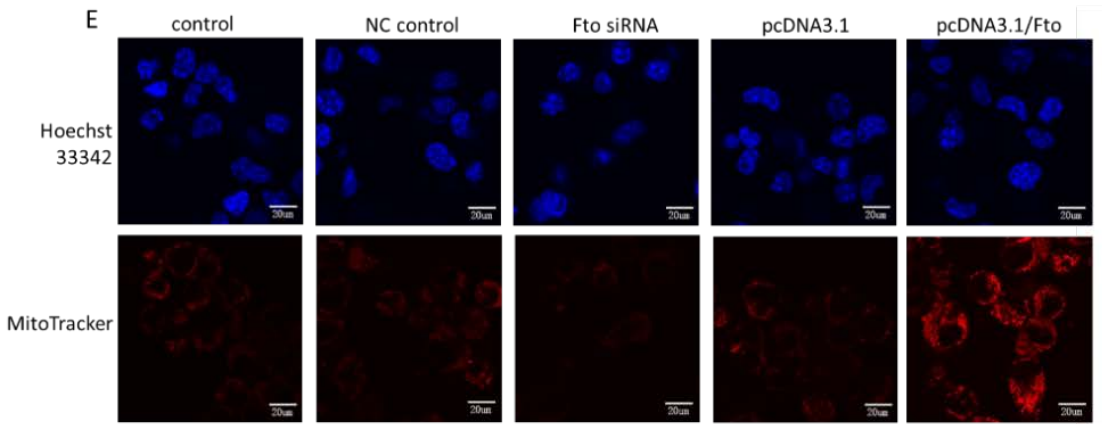

$\mathrm{F}$
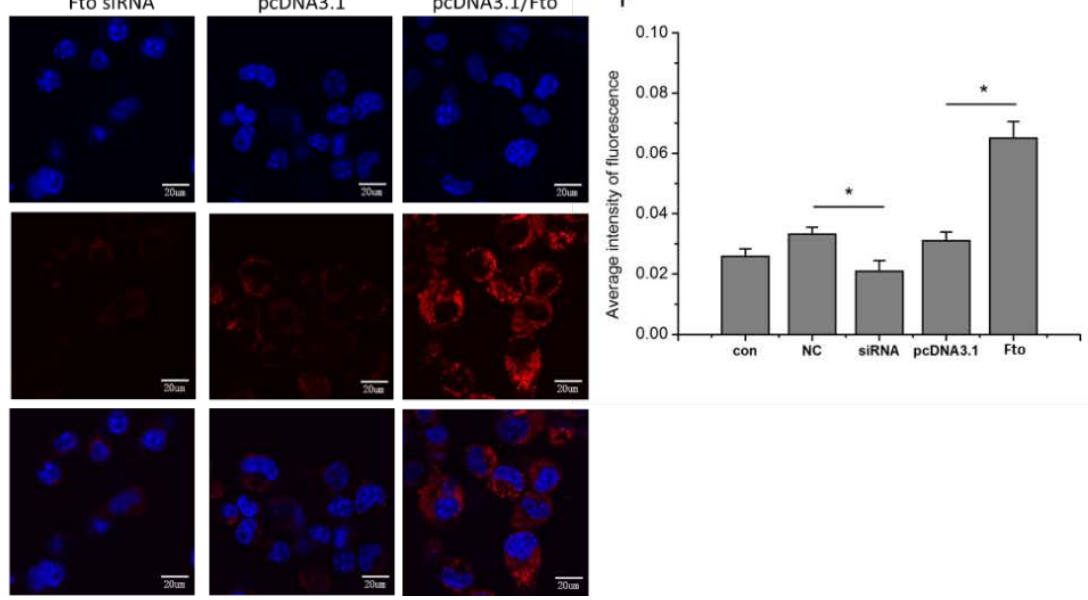

Figure 3. Fto influenced the mitochondrial membrane potential and ATP generation of pre-adipocytes. (A,B) Mitochondrial membrane potential of 3T3-L1 cells were determined using JC-1, $24 \mathrm{~h}$ after transfection. The ratio of aggregated JC- 1 and monomeric JC-1 represented $\Delta \psi \mathrm{m}$ of cells. Results are expressed as the means \pm SD from three independent experiments. ${ }^{*} p<0.05$ versus NC/empty pcDNA3.1 vector group. (C,D) Cellular ATP concentrations were detected in 3T3-L1 cells $24 \mathrm{~h}$ after transfection. Results are expressed as the means \pm SD from 3 independent experiments. ${ }^{*} p<0.05$ versus NC/empty pcDNA3.1 vector group. (E) Parental and mock transfected control 3T3-L1 cells, together with Fto-deficient or Fto-overexpressed pre-adipocytes were incubated with MitoTracker Red $\mathrm{CM}-\mathrm{H}_{2} \mathrm{X}_{\mathrm{Ros}}$ staining, $24 \mathrm{~h}$ after transfection. The images were visualized by fluorescence microscopy as shown above; scale bar, $20 \mu \mathrm{m}$. (F) Quantification analysis of MitoTracker fluorescence intensity.

Live cell imaging of mitochondria using Mitotracker Red CM- $\mathrm{H}_{2} \mathrm{X}_{\mathrm{Ros}}$ staining was performed to investigate the effects of modulating Fto expression. The fluorescence dye MitoTracker Red CM- $\mathrm{H}_{2} \mathrm{X}_{\mathrm{Ros}}$ is cell-permeable and sequesters in the mitochondria. This dye does not emit fluorescence unless it is 
oxidized; thus the observed fluorescence implies the presence of actively respiring mitochondria [24]. In the present study, decreased fluorescence was observed in Fto-deficient 3T3-L1 cells when compared with NC controls (Figure 3E) while enhanced MitoTracker Red fluorescence was observed in the context of Fto-overexpression. Specifically, Fto-overexpression resulted in a two-fold increase in the fluorescence intensity as compared to vector-transfected 3T3-L1 cells (Figure 3E,F).

Cellular ATP content was also evaluated. As shown in Figure 3C,D, the cellular ATP level decreased in the Fto knockdown 3T3-L1 cells while Fto-overexpression enhanced luminance by up to two fold compared with mock transfection groups. The results were in agreement with MMP and Mitotracker staining results and together suggested that Fto might play a role in the regulation of mitochondrial activity of pre-adipocytes.

\subsection{Fto Gene Regulated the Differentiation of Pre-adipocyte}

Derived from mouse 3T3 cells, 3T3-L1 has the ability to differentiate into adipocytes. The effect of Fto on 3T3-L1 cells differentiation was detected using intracellular lipid droplets staining assay. As shown in Figure 4, following induction of differentiation, the lipid droplets in 3T3-L1 cells with Fto-suppression were irregular and smaller, and the amount of differentiated cells was significantly less than the amount observed in NC control group $(p<0.05)$. By contrast, Fto-overexpression led to more cellular lipid droplets and more differentiated cells as compared to the mock transfection group under typical culture conditions $(p<0.05)$.

A
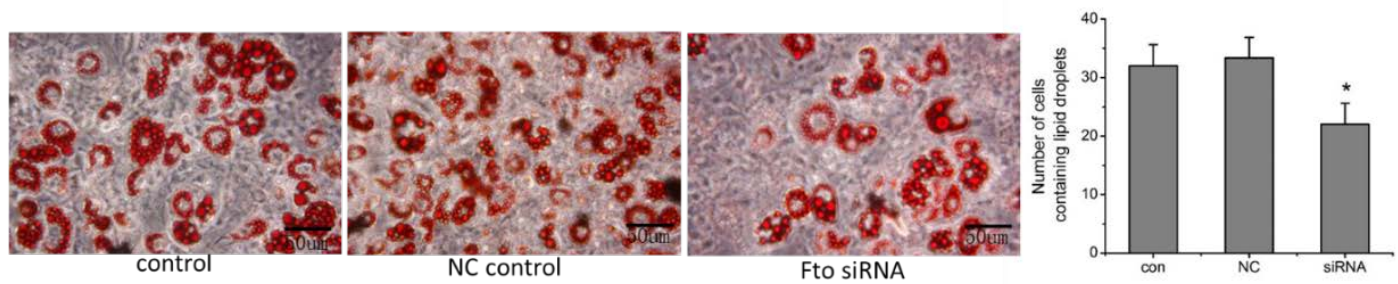

B
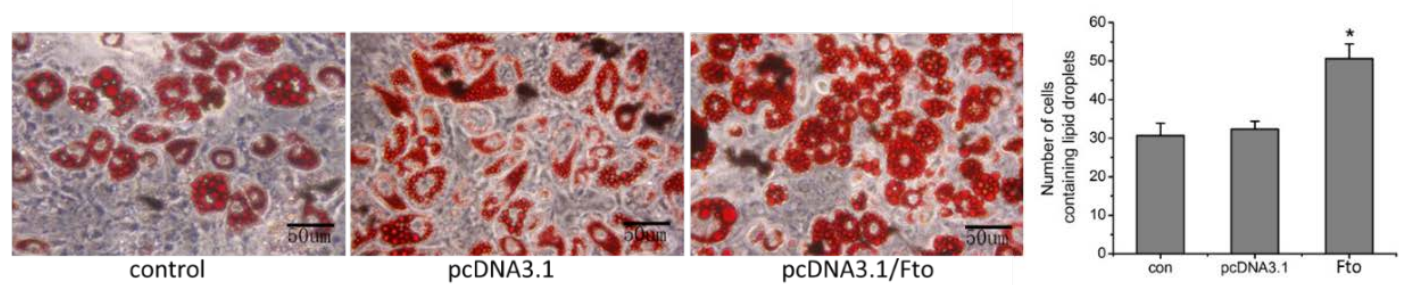

Figure 4. Effects of Fto on 3T3-L1 cells differentiation: (A) The NC control and Fto siRNA transfected 3T3-L1 cells, together with parental pre-adipocytes were treated with differentiation media at $24 \mathrm{~h}$ after transfection, and were subsequently incubated for 10 to 14 days. Cells were fixed and stained with Oil Red $\mathrm{O}$. Then the cells were photographed under a phase contrast microscope, and five randomly selected microscopic fields for each group were then counted; scale bar, $50 \mu \mathrm{m}$. ${ }^{*} p<0.05$ versus NC group. (B) The differentiation of Fto overexpressed 3T3-L1 cells were assayed as described above. * $p<0.05$ versus empty pcDNA3.1 vector group.

\subsection{Fto Regulated the Differentiation and Proliferation of 3T3-L1 Cells via Multiple Mechanisms}

To examine the contributions of Fto in regulating differentiation and proliferation, the expression of several lipid metabolism-related transcription factors and signaling pathways were detected in Fto knockdown or overexpressed 3T3-L1 cells. The results showed that knockdown of Fto decreased the expression of peroxisome proliferator-activated receptor $\gamma$ (PPAR $\gamma$ ) in addition to significantly suppressing Akt phosphorylation and the expression of Glucose transporter type 4 (GLUT4) (Figure 5A,C). No obvious effects on the expression of AMP-activated protein kinase (AMPK), adipose triglyceride lipase (ATGL), hormone-sensitive lipase (HSL) and cAMP response 
element-binding protein CREB were observed (Figure 5A). Fto overexpression has the opposing effect as Fto-knockdown (Figure 5B). We noticed increased HSL in 3T3-L1 cells with elevated Fto expression. Wortmannin (100 nmol/L, Cayman Chemical, Ann Arbor, MA, USA), which is a specific inhibitor of the phosphatidylinositol 3-kinase (PI3k)/Akt signaling cascade, was utilized to investigate the effect of Fto on the proliferation and differentiation. As shown in Figure 5D, phospho-Akt was markedly reduced in Fto-overexpressing 3T3-L1 cells following application of Wortmannin, suggesting that Fto mediates the phosphorylation of Akt at serine 473. These results indicate that Fto might be a multi-functional regulator in pre-adipocytes proliferation and differentiation.
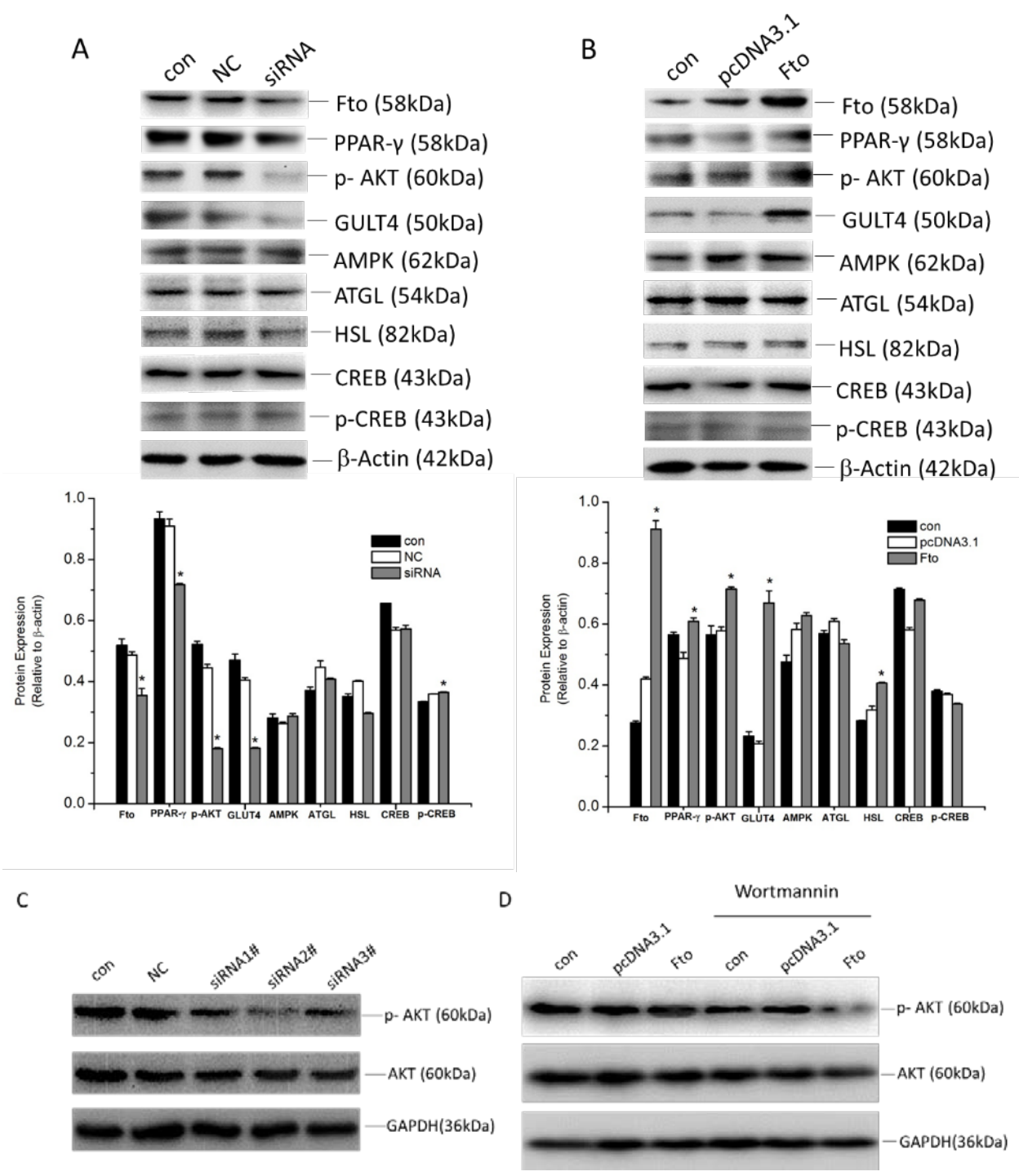

Figure 5. Effect of Fto on proliferation and differentiation of pre-adipocyte. (A) 3T3-L1 cells transfected with/without NC siRNA or Fto siRNA, as well as (B) Fto recombinant plasmid or vector "mock" transfected 3T3-L1 cells were harvested $24 \mathrm{~h}$ after transfection for protein extraction and quantified. Fifty microgram of total protein were analyzed by Western blot. Expressions and activities of specific transcription factors and signaling factors were detected. The expression level was displayed as fold changes in band density. Results are expressed as the means \pm SD from three independent experiments. * $p<0.05$, vs. the mock transfection group. (C) Further, three different Fto siRNA were transfected into 3T3-L1 cells for $24 \mathrm{~h}$. The phosphor-Akt and Akt expression were examined by Western blot assay. (D) 3T3-L1 cells were transfected with vector plasmid and Fto plasmid for $24 \mathrm{~h}$, then were cultured in the absence or presence of the PI3k inhibitor (Wortmannin, $100 \mathrm{nmol} / \mathrm{L}$ ) for $24 \mathrm{~h}$. The expression level of phospho-Akt and Akt was determined by Western blot analysis. 


\section{Discussion}

White adipose tissues are distributed throughout the whole body, and the excessive accumulation of WAT is thought to account for obesity [2,8,9]. Pre-adipocytes are the precursors of the adipocytes, which consist of WAT, and regulation of the balance between proliferation and differentiation of these cells will determine the quantity and size of mature adipocytes [12]. As such, dysregulation of proliferation and differentiation in pre-adipocytes contributes to the onset of obesity.

Fisher et al. [15] previously demonstrated that mice lacking the Fto gene suffered from severe growth retardation. In the present study, we observed a significant inhibition of proliferation in Fto knockdown 3T3-L1 cells (Figure 2A,C), which is consistent with the in vivo results of Fisher et al. A newly published study by Jeffery et al. [25] indicated that increased proliferation of adipocyte precursors in visceral WAT during the early stage of high fat diet caused adipogenesis. Using mouse embryonic fibroblasts (MEF) derived from Fto-deleted or Fto-overexpressed mice, Merkestein et al. [20] found that FTO could enhance MEF proliferation as early as $48 \mathrm{~h}$ after adipogenic induction. In our study, by applying Fto siRNA or recombinant plasmid transfection, we demonstrated that Fto could regulate the proliferation of 3T3-L1 cell line in the precursor status, and even earlier during adipogenesis (24 $\mathrm{h}$ after adipogenic induction) (Figure $2 \mathrm{~A}-\mathrm{C}$ ). These results confirmed the regulatory role of Fto in adipogenesis in vitro.

As a well-characterized cell model, fibroblast-like 3T3-L1 cells will differentiate into a signet ring appearance of adipocyte-like phenotype under appropriate stimulation, which represents the synthesis and accumulation of triglycerides [26]. Several studies have reported that Fto-overexpression can significantly increase the triglyceride content of the cell $[17,27,28]$. Merkestein et al. [20] recently reported that primary adipocytes and MEFs derived from Fto overexpression mice demonstrated increased potential for adipogenic differentiation while Fto knockout mice derivative MEFs exhibited reduced adipogenesis. In our study, following differentiation stimulation, we found Fto-overexpressing cells can differentiate into more mature adipocytes with more lipid droplets than vacant plasmid transfected cells (Figure 4B). By contrast, less, irregular and smaller lipid droplets were observed after differentiation induction in Fto siRNA transfected pre-adipocytes (Figure 4A). Our in vitro data were in agreement with the finding of Merkestein et al. [20] that FTO affects fat mass via regulating adipocyte differentiation in vivo.

Several studies have suggested that Fto expression level was strongly correlated with energy status. For example, overexpression of Fto led to fatty acid accumulation and increased food intake and thus resulted in obesity [17]. Tews et al. [19] recently reported that FTO is involved in WAT browning in human SGBS pre-adipocytes. Although they showed no difference in the rate of differentiation and triglyceride content between control and FTO-deficient SGBS cells, they determined that FTO deficiency could lead to mitochondrial uncoupling and increase energy expenditure [19]. In the present study, we found that Fto could regulate the MMP of mouse pre-adipocyte 3T3-L1 and affect ATP generation in 3T3-L1 cells. Our MTT assay results also indicated effects of Fto on the mitochondrial activity of live 3T3-L1 cells, since the conversion of MTT into formazan requires the functioning mitochondria. Based on these results, we hypothesize that FTO might affect the mitochondrial function in vitro. However, considering that Tews et al. did not show significantly varied citrate synthase activity, mitochondrial contents and structure in FTO deficient SGBS cells [20], we should carefully analyze the effects of Fto on mitochondrial function in our model system in future studies to fully characterize the implications of our findings. Nevertheless, our results clearly indicated that Fto could represent a functional regulator on the 3T3-L1 pre-adipocyte in the context of obesity.

There are numerous opinions regarding the formation of adipose tissue in the development and expansion of adipose tissue in obesity [25]. Jeffery et al. [25] recently suggested that the formation of adipocytes in obesity and development is controlled by distinct molecular mechanisms. Fat accumulation and morphology changes of adipocytes were thought to represent a consequence of specific genes expression, including several transcription factors, positive and negative signaling pathways effectors, and even non-coding RNAs, which were induced during the process of 
pre-adipocytes proliferation and differentiation [11,12]. In this study, we wanted to identify molecular mechanisms and signaling pathways that regulated pre-adipocyte proliferation and differentiation via Fto.

Our data demonstrate that $F$ to overexpression induced the expression of transcription activator $\operatorname{PPAR} \gamma$, while Fto deficiency impaired PPAR $\gamma$ expression in 3T3-L1 pre-adipocyte. PPAR $\gamma$ belongs to the ligand-activated nuclear receptor superfamily, which is preferentially expressed in adipocytes [29], and is vital in expression regulation of the gene networks involved in adipogenesis, lipid metabolism, inflammation and maintenance of metabolic homeostasis [29,30]. In 2013, Bravard et al. [31] hypothesized that FTO might participate in the increased expression of PPAR $\gamma 2$ during adipogenesis via demethylating its promoter region, but the subsequent study failed to verify their hypothesis. Further studies are required to clarify the mechanistic actions of FTO on PPAR $\gamma$ expression regulation during adipogenesis.

We found Fto may also be involved in Akt activity regulation in 3T3-L1 cells. The insulin-mediated activation of PI3K/Akt signaling pathway plays a crucial role in energy metabolism [32-34]. Activated Akt can induce glycogen synthesis by inhibiting GSK-3, promote protein synthesis via mTOR cascades, and facilitate cell survival through inhibiting pro-apoptotic factors [32,34]. The insulin receptor signaling is also important for fatty acid and cholesterol synthesis [35]. The activation of adipocyte precursors is thought to dependent on the PI3K-AKT2 pathway in multiple models of obesity, but Jeffery et al. [25] demonstrated that WAT-development does not require AKT2. However, using a specific PI3k inhibitor, we found that Akt signaling is involved in Fto regulated adipogenesis in vitro (Figure 5). Moreover, in the present study, the regulation of Fto on Akt activity could in part interpret the variations of proliferation, energy homeostasis, and adipogenesis in 3T3-L1 cells with different Fto levels. Besides, Fto expression levels similarly affected GLUT4 expression, which also participates in insulin receptor signaling [36]. We were also able to conclude that FTO had a minor effect on HSL expression (following Fto-overexpression) and no effect on the expression of AMPK and ATGL.

In summary, our study demonstrates that Fto can affect the proliferation, energy homeostasis, and differentiation of 3T3-L1 pre-adipocyte. Fto might function as a regulator of PI3K Akt signaling and PPAR $\gamma$ expression. While our results have improved our understanding of the importance of Fto on obesity, several questions remain to be answered. Specifically, further studies are required to determine if the Fto-mediated effect on PPAR $\gamma$ is mediated through demethylation activity or via other mechanism. Similarly, the exact mechanisms through which Fto affects Akt phosphorylation requires attention. More detailed investigations using more sophisticated model system (primary adipocytes, embryonic fibroblasts, etc.) are extremely necessary to uncover the molecular mechanisms underlying Fto's role in adipogenesis and obesity.

Acknowledgments: This study was supported by grants from the National Science Foundation of China (81273067, 81302382 and 81472974), and the Priority Academic Program Development of Jiangsu Higher Education Institutions.

Author Contributions: Yang Jiao and Liqiang Qin conceived and designed the experiments; Jingying Zhang performed the experiments; Lunjie $\mathrm{Lu}$ and Jiaying $\mathrm{Xu}$ analyzed the data; Jiaying $\mathrm{Xu}$ contributed reagents and materials; and Yang Jiao and Liqiang Qin wrote the paper. All authors have read and approved the final manuscript.

Conflicts of interest: The authors declare no conflict of interest.

\section{References}

1. Heindel, J.J.; Newbold, R.; Schug, T.T. Endocrine disruptors and obesity. Nat. Rev. Endocrinol. 2015, 11, 653-661. [CrossRef] [PubMed]

2. Abente, E.J.; Subramanian, M.; Ramachandran, V.; Najafi-Shoushtari, S.H. Micrornas in obesity-associated disorders. Arch. Biochem. Biophys. 2015, 589, 108-119. [CrossRef] [PubMed]

3. Hebert, J.R.; Allison, D.B.; Archer, E.; Lavie, C.J.; Blair, S.N. Scientific decision making, policy decisions, and the obesity pandemic. Mayo Clin. Proc. 2013, 88, 593-604. [CrossRef] [PubMed] 
4. WHO. Global status report on noncommunicable diseases 2014. Available online: http://apps.who.int/ iris/bitstream/10665/148114/1/9789241564854_eng.pdf?ua=1 (accessed on 15 February 2016).

5. Butsch, W.S. Obesity medications: What does the future look like? Curr. Opin. Endocrinol. Diabetes Obes. 2015, 22, 360-366. [CrossRef] [PubMed]

6. McMorrow, A.M.; Connaughton, R.M.; Lithander, F.E.; Roche, H.M. Adipose tissue dysregulation and metabolic consequences in childhood and adolescent obesity: Potential impact of dietary fat quality. Proc. Nutr. Soc. 2015, 74, 67-82. [CrossRef] [PubMed]

7. Goossens, G.H.; Blaak, E.E. Adipose tissue dysfunction and impaired metabolic health in human obesity: A matter of oxygen? Front. Endocrinol. 2015, 6. [CrossRef] [PubMed]

8. Rutkowski, J.M.; Stern, J.H.; Scherer, P.E. The cell biology of fat expansion. J. Cell Biol. 2015, 208, 501-512. [CrossRef] [PubMed]

9. Ma, X.; Lee, P.; Chisholm, D.J.; James, D.E. Control of adipocyte differentiation in different fat depots; implications for pathophysiology or therapy. Front. Endocrinol. 2015, 6. [CrossRef] [PubMed]

10. Zhou, Y.T.; Wang, Z.W.; Higa, M.; Newgard, C.B.; Unger, R.H. Reversing adipocyte differentiation: Implications for treatment of obesity. Proc. Natl. Acad. Sci. USA 1999, 96, 2391-2395. [CrossRef] [PubMed]

11. Wang, N.; Wang, X.; Shi, M.; Shi, H.; Yan, X.; Li, H.; Wang, S.; Wang, Y. LMO4 modulates proliferation and differentiation of 3T3-L1 preadipocytes. FEBS Lett. 2013, 587, 3032-3037. [CrossRef] [PubMed]

12. Gregoire, F.M. Adipocyte differentiation: From fibroblast to endocrine cell. Exp. Biol. Med. 2001, 226, 997-1002.

13. Frayling, T.M.; Timpson, N.J.; Weedon, M.N.; Zeggini, E.; Freathy, R.M.; Lindgren, C.M.; Perry, J.R.; Elliott, K.S.; Lango, H.; Rayner, N.W.; et al. A common variant in the fto gene is associated with body mass index and predisposes to childhood and adult obesity. Science 2007, 316, 889-894. [CrossRef] [PubMed]

14. Dina, C.; Meyre, D.; Gallina, S.; Durand, E.; Korner, A.; Jacobson, P.; Carlsson, L.M.; Kiess, W.; Vatin, V.; Lecoeur, C.; et al. Variation in FTO contributes to childhood obesity and severe adult obesity. Nat. Genet. 2007, 39, 724-726. [CrossRef] [PubMed]

15. Fischer, J.; Koch, L.; Emmerling, C.; Vierkotten, J.; Peters, T.; Bruning, J.C.; Ruther, U. Inactivation of the Fto gene protects from obesity. Nature 2009, 458, 894-898. [CrossRef] [PubMed]

16. Zhao, X.; Yang, Y.; Sun, B.F.; Zhao, Y.L.; Yang, Y.G. FTO and obesity: Mechanisms of association. Curr. Diabetes Rep. 2014, 14. [CrossRef] [PubMed]

17. Church, C.; Moir, L.; McMurray, F.; Girard, C.; Banks, G.T.; Teboul, L.; Wells, S.; Bruning, J.C.; Nolan, P.M.; Ashcroft, F.M.; et al. Overexpression of Fto leads to increased food intake and results in obesity. Nat. Genet. 2010, 42, 1086-1092. [CrossRef] [PubMed]

18. Zhao, X.; Yang, Y.; Sun, B.F.; Shi, Y.; Yang, X.; Xiao, W.; Hao, Y.J.; Ping, X.L.; Chen, Y.S.; Wang, W.J.; et al. FTO-dependent demethylation of N6-methyladenosine regulates mRNA splicing and is required for adipogenesis. Cell Res. 2014, 24, 1403-1419. [CrossRef]

19. Tews, D.; Fischer-Posovszky, P.; Fromme, T.; Klingenspor, M.; Fischer, J.; Ruther, U.; Marienfeld, R.; Barth, T.F.; Moller, P.; Debatin, K.M.; et al. FTO deficiency induces UCP-1 expression and mitochondrial uncoupling in adipocytes. Endocrinology 2013, 154, 3141-3151. [CrossRef] [PubMed]

20. Merkestein, M.; Laber, S.; McMurray, F.; Andrew, D.; Sachse, G.; Sanderson, J.; Li, M.; Usher, S.; Sellayah, D.; Ashcroft, F.M.; et al. FTO influences adipogenesis by regulating mitotic clonal expansion. Nat. Commun. 2015, 6. [CrossRef] [PubMed]

21. Nie, L.; Zhou, J.; Wang, L.; Qin, S.; Xu, X. Effects of FTO gene on the radiosensitivity of A172 cells and its mechanism. Chin. J. Radiol. Med. Prot. 2015, 35, 252-256.

22. Jiao, Y.; Sun, K.K.; Zhao, L.; Xu, J.Y.; Wang, L.L.; Fan, S.J. Suppression of human lung cancer cell proliferation and metastasis in vitro by the transducer of ErbB-2.1 (TOB1). Acta Pharmacol. Sin. 2012, 33, 250-260. [CrossRef] [PubMed]

23. Parker, V.E.R.; Knox, R.G.; Zhang, Q.; Wakelam, M.J.O.; Semple, R.K. Phosphoinositide 3-kinase-related overgrowth: Cellular phenotype and future therapeutic options. Lancet 2015, 385. [CrossRef]

24. Paxinou, E.; Weisse, M.; Chen, Q.; Souza, J.M.; Hertkorn, C.; Selak, M.; Daikhin, E.; Yudkoff, M.; Sowa, G.; Sessa, W.C.; et al. Dynamic regulation of metabolism and respiration by endogenously produced nitric oxide protects against oxidative stress. Proc. Natl. Acad. Sci. USA 2001, 98, 11575-11580. [CrossRef] [PubMed]

25. Jeffery, E.; Church, C.D.; Holtrup, B.; Colman, L.; Rodeheffer, M.S. Rapid depot-specific activation of adipocyte precursor cells at the onset of obesity. Nat. Cell Biol. 2015, 17, 376-385. [CrossRef] [PubMed] 
26. Cristancho, A.G.; Lazar, M.A. Forming functional fat: A growing understanding of adipocyte differentiation. Nat. Rev. Mol. Cell Biol. 2011, 12, 722-734. [CrossRef] [PubMed]

27. Zhang, M.; Zhang, Y.; Ma, J.; Guo, F.; Cao, Q.; Zhang, Y.; Zhou, B.; Chai, J.; Zhao, W.; Zhao, R. The demethylase activity of FTO (fat mass and obesity associated protein) is required for preadipocyte differentiation. PLOS ONE 2015, 10. [CrossRef] [PubMed]

28. Guo, J.; Ren, W.; Li, A.; Ding, Y.; Guo, W.; Su, D.; Hu, C.; Xu, K.; Chen, H.; Xu, X.; et al. Fat mass and obesity-associated gene enhances oxidative stress and lipogenesis in nonalcoholic fatty liver disease. Dig. Dis. Sci. 2013, 58, 1004-1009. [CrossRef] [PubMed]

29. Ahmadian, M.; Suh, J.M.; Hah, N.; Liddle, C.; Atkins, A.R.; Downes, M.; Evans, R.M. PPAR $\gamma$ signaling and metabolism: The good, the bad and the future. Nat. Med. 2013, 99, 557-566. [CrossRef] [PubMed]

30. Janani, C.; Ranjitha Kumari, B.D. PPAR gamma gene-A review. Diabetes Metab. Syndr. Clin. Res. Rev. 2015, 9, 46-50. [CrossRef] [PubMed]

31. Bravard, A.; Veilleux, A.; Disse, E.; Laville, M.; Vidal, H.; Tchernof, A.; Rieusset, J. The expression of FTO in human adipose tissue is influenced by fat depot, adiposity, and insulin sensitivity. Obesity 2013, 21, 1165-1173. [CrossRef] [PubMed]

32. Fischer-Posovszky, P.; Tews, D.; Horenburg, S.; Debatin, K.M.; Wabitsch, M. Differential function of Akt1 and Akt2 in human adipocytes. Mol. Cell Endocrinol. 2012, 358, 135-143. [CrossRef] [PubMed]

33. Chen, J.; Zhao, K.N.; Li, R.; Shao, R.; Chen, C. Activation of PI3K/Akt/mTOR pathway and dual inhibitors of PI3K and mTOR in endometrial cancer. Curr. Med. Chem. 2014, 21, 3070-3080. [CrossRef] [PubMed]

34. Mosca, E.; Barcella, M.; Alfieri, R.; Bevilacqua, A.; Canti, G.; Milanesi, L. Systems biology of the metabolic network regulated by the Akt pathway. Biotechnol. Adv. 2012, 30, 131-141. [CrossRef] [PubMed]

35. Wong, R.H.; Sul, H.S. Insulin signaling in fatty acid and fat synthesis: A transcriptional perspective. Curr. Opin. Pharmacol. 2010, 10, 684-691. [CrossRef] [PubMed]

36. Chang, L.; Chiang, S.H.; Saltiel, A.R. Insulin signaling and the regulation of glucose transport. Mol. Med. 2004, 10, 65-71. [PubMed]

(C) 2016 by the authors; licensee MDPI, Basel, Switzerland. This article is an open access article distributed under the terms and conditions of the Creative Commons by Attribution (CC-BY) license (http://creativecommons.org/licenses/by/4.0/). 